\title{
A COMPARISON OF PROGRESSIVE-FAILURE CRITERIA IN THE PREDICTION OF THE DYNAMIC BENDING FAILURE OF COMPOSITE LAMINATED BEAMS
}

\author{
C. Santiuste, S. Sánchez-Sáez and E. Barbero* \\ Department of Continuum Mechanics and Structural Analysis. \\ University Carlos III of Madrid \\ Avda. de la Universidad 30, 28911 Leganés, Madrid, Spain
}

Phone: +34 9162499 65; Fax: +34 9162494 30; email: ebarbero@ing.uc3m.es

\begin{abstract}
Hou and Hashin criteria were compared under dynamic conditions, analyzing the failure of beams subjected to low velocity impacts in a three point configuration. To accomplish this goal a progressive failure model was implemented in a finite element code to predict the failure modes (fibre tensile failure, fibre compressive failure, matrix cracking, matrix crushing, and delamination), considering both Hou and Hashin criteria. The experimental results, from tests conducted in a drop-weight tower and available in the literature, were used to validate the numerical model. This model, using both criteria, was used to analyse the failure modes of two lay-ups (unidirectional and crossply) tested in two experimental devices (drop-weight tower and split Hopkinson pressure bar). The main failure mechanisms in both laminate lay-ups were also identified.
\end{abstract}

Keywords: Laminates, Impact behaviour, Finite element analysis, failure criteria

\section{INTRODUCTION}

Composite materials are being increasingly used in many industrial applications thanks to their excellent mechanical properties and low specific weight. Some of these composite structures, such as robot arms, drive shafts, and helicopter blades, may be modelled, at least in a preliminary design, as beams subjected to loads that undergo mainly bending moments. However, composite structures subjected to low-velocity impacts or the drop of minor objects, such as tools during assembly or maintenance operation, exhibit a brittle behaviour and can sustain significant damage. These impacts are particularly dangerous because they can drastically impair the mechanical behaviour of the structure after impact with little or no visible damage. The damage inflicted on a composite structure is a complex phenomenon due to the many parameters that could intervene [1] This problem has been studied by numerous researchers, primarily analysing the impact on plates [2-8], and less on beams [9-11]. However, better knowledge of the damage mechanisms and their evolution in composite beams is still 
necessary to improve the modelling of the damage for a better numerical assessment of their mechanical characteristics and thereby optimise their design.

Of the different techniques to predict composite-damage mechanisms, the failurecriteria approach has proved to be an accurate method to predict the failure of many composite applications, under both static and dynamic conditions. The failure of a lamina does not produce the complete breakage of the laminate, thus the analysis of the damage evolution requires not only a failure criteria but also a mechanical properties degradation procedure [12]. Many sets of failure criteria can be found in the literature $[13,14]$. Although criteria such as the maximum-stress criterion or Tsai-Wu criterion have been used in several works $[15,16]$, the complex failure of composite materials requires sets of criteria to predict different failure modes (matrix crack, fibre failure, delamination, etc.). The evolution of the failure modes can be independent or simultaneous, depending on the stress field [17]. An international exercise was developed between 1998 and 2004 to compare the most important failure criteria used under static conditions (Composite Science and Technology, vols. 58, 62 and 64). Despite the research efforts, a consensus on selecting the best criteria to predict the composite failure has not been reached, especially in events with out-of-plane loads. In spite of the lack of a comparable study under dynamic conditions the most common failure criteria used in the analysis of impact problems are those of Hashin [18] and Hou [19], constituting a three-dimensional version of Chang-Chang criteria [20]. Although both Hashin and Hou criteria are expressed in terms of stresses, they consider different failure mechanism and equations. Hashin criteria have been applied on laminated plates in low-velocity impacts $[6,21,22]$ to estimate load history, and in high-velocity impacts to study the damage area and absorbed energy [4, 7, 8, 23]. Chang-Chang and Hou criteria have also been applied in analysing the behaviour of composite laminated plates subjected to impact at low [2, 24, 25] and high velocities [11, 26]. These criteria have also been applied in the study of sandwich structures subjected to impact, both in plates [27-30] and beams [31]. With these failure criteria the indentation, damage area [27-28] and history load [28-30] was evaluated.

These criteria have been used in several dynamic problems with different laminates, geometries and load conditions but there is a lack of comparisons between the most common criteria to be used as selection tools to choose the proper criteria in each problem. To help in the selection of accurate failure criteria in dynamic conditions in this work the behaviour of composite beam under low velocity impact was analysed. Impacts over beams produce several internal forces which originate a three-dimensional field, so that the analysis cannot be treated by a plane model [11]. Hence a rigorous analysis based on 3D progressive-damage models is required to analyse the composite beam behaviour under dynamic conditions.

The purpose of the present work is to compare the accuracy of Hou and Hashin criteria in predicting the failure of composite laminated beams under dynamic conditions. A three-dimensional finite element model was implemented in the FE commercial code 
ABAQUS/Explicit to simulate out-of-plane impacts on laminated beams. The numerical models were validated using low-velocity impact tests and experimental data reported by a previous work [10] and Hallett [9]. The analysis performed leads to several conclusions on the selection between both Hashin and Hou failure criteria to predict the failure of different laminate lay-ups in composite beams under dynamic conditions.

\section{FAILURE CRITERIA}

As stated above, the composite-failure criteria of Hou [19] are based on the well-known Chang-Chang criteria [20]. Hou criteria consider four failure modes: fibre failure, matrix cracking, matrix crushing and delamination, assuming a quadratic interaction between stresses in the four failure modes, Table 1.

Hashin failure criteria consider that there are also four modes of failure, but slightly different, fibre and matrix failure, both under tensile and compression stress. Hashin does not consider failure by delamination. Each mode is governed by the component of the stress vector associated with the failure plane by a quadratic equation. There are several expressions of Hashin criteria [4, 32], in this work the three-dimensional formulation described in Hashin [4] was used.

The formulation of both criteria is detailed below:

- Fibre tension: the formulation of Hou and Hashin criteria is the same. This failure is due to the combination of axial stress and shear stresses, and it is analysed by a quadratic interaction of $\sigma 11 \sigma 12$ and $\sigma 13$. Adding shear stress to the fibre-breakage criterion may result in the underestimation of the laminate strength, and therefore some authors add a weighting factor to model the interaction between shear and tensile stress [29]. In this work, the weighting factor was stated as 1 to consider the effect of shear stresses in the fibre failure mechanism, as many authors are used to do.

- Fibre compression: This criterion is different in Hashin and Hou criteria. Hashin criteria consider only fibre-direction stress, $\sigma_{11}$, in a linear way; meanwhile, Hou criteria consider the same formulation as in the tensile fibre-breakage criterion. Matrix cracking and matrix crushing: Hou criteria consider the stresses in transverse direction, $\sigma_{22}, \sigma_{23}$, and $\sigma_{12}$ while Hashin criteria also consider stresses in the normal direction, $\sigma_{33}$ and $\sigma_{13}$. Hashin failure criteria consider in the matrix-failure formulation a quadratic interaction between stress invariants, due to the impossibility of determining the plane of failure. In this failure mode the stress $\sigma_{11}$ is not considered due to the fact that any possible plane of failure is parallel to the fibres and, therefore, the component of the stress vector of any of these planes do not depend on $\sigma_{11}$. The linear term resulting from the interaction between invariants is maintained in Hashin matrix crushing criterion, while it is removed in the matrix cracking criterion.

- Delamination: The delamination criterion used in Hou criteria is based on the one proposed by Kim and Soni [33] and modified by Brewer and Lagace [34]. 
This quadratic stress based criterion is widely used by many researchers[35]. Hou modified their equation [19] considering that compressive through-thethickness stresses $\left(\sigma_{33}<0\right)$ avoid delamination, and thus the delamination criterion was used in the present work only for normal tensile stresses. Due to Hashin formulation do not consider the delamination mode, in this work, and in order to compare both criteria, Hou delamination failure criterion was included in the Hashin formulation.

The variables in Table 1 are:

- $\sigma_{11}, \sigma_{22}$, and $\sigma_{33}$, are the stresses in the fibre direction, transverse direction, and through-the-thickness direction, respectively;

- $\sigma_{12}, \sigma_{23}$, and $\sigma_{31}$, are the shear stresses in the fibre and transverse plane, the transverse and through-thickness plane, and the fibre and through-thickness plane, respectively;

- $\mathrm{X}_{\mathrm{T}}$ and $\mathrm{X}_{\mathrm{C}}$ are the tensile and compressive strengths in the fibre direction;

- $\mathrm{Y}_{\mathrm{T}}$ and $\mathrm{Y}_{\mathrm{C}}$ are the tensile and compressive strengths in the transverse direction;

- $\mathrm{Z}_{\mathrm{T}}$ is the tensile strength in the through-thickness direction;

- $\mathrm{S}_{\mathrm{L}}$ is the longitudinal shear strength;

- $\mathrm{S}_{\mathrm{T}}$ is the transverse shear strength.

\section{EXPERIMENTAL TEST FOR MODEL VALIDATION}

A three-dimensional numerical model was used to compare the accuracy of the failure criteria in the prediction of the failure of composite beams under dynamic conditions. Different laminate lay-ups, specimen spans and experimental devices were used to validate the numerical model. The experimental data used to validate the numerical model were taken from the literature [9], from a previous work [10] and from experimental tests developed in the present work. A total of six sets of impact tests were used in the model validation (table 2): First low-velocity impact tests were performed using a drop-weight tower, over unidirectional laminate beams to verify the accuracy of the numerical model under variations in the impact energy and the span ratio (UN1, $\mathrm{UN} 2$, and UN3) and over cross-ply laminate beams used to verify the precision of the numerical simulations over cross-ply laminate beams (CP1) [10]. Second, Hopkinsonbar tests were made over cross-ply laminate beams used to predict the beam failure in a different test device (CP2 and $\mathrm{CP} 3)$ [9].

In the impact tests carried out in this work (UN1, UN2, and UN3), a unidirectional laminate made up of ten plies of carbon fibre (AS4) and epoxy resin (3501-6) and $2 \mathrm{~mm}$ of thickness was used. This laminate is frequently used in the aeronautical industry because of its good specific properties.

These tests were performed using a three-point bending configuration in a drop-weight tower, CEAST Fractovist 6785, instrumented to register the load exerted by the impactor. An impactor of $3.86 \mathrm{~kg}$ of mass and Charpy nose was used, as can be seen in Fig.2. Seven specimens were tested for each configuration (UN1, UN2 and UN3) at two impact velocities, 3.06 and $3.37 \mathrm{~m} / \mathrm{s}$. Each test provided a record of the load applied to 
the specimen by the impactor. Fig. 1 shows the history load of a representative specimen for each configuration. The peak load (maximum value of the load history) for UN1 specimens is higher than in the other two configurations, due to its lower span ratio. In both, UN2 and UN3 specimens the peak loads are similar. The peak load and maximum displacement for the configurations tested in this work are shown in table 3.

The displacement history of the impactor could be calculated by integrating the load history showed in Fig. 1 with the use of impact velocity, Eq.(1).

$$
x(t)=\int_{0}^{t}\left[v_{0}-\int_{0}^{t} \frac{F(t)-m \cdot g}{m} d t\right] d t
$$

where $v_{0}$ is the impact velocity, $F(t)$ the load history, $m$ the impactor mass and $g$ the acceleration of gravity.

The impact velocity could be estimated by the height from which the impactor is dropped; nevertheless, when the impactor reached the specimen, the velocity was lower than predicted, due to the friction undergone during the fall. For an accurate calculation of the impact velocity, tests were recorded by a high-speed video camera Photron APX RS, which allowed 20,000 images to be taken per second. This technique also enabled an evaluation of the failure mode of the specimens.

\section{NUMERICAL MODEL}

\subsection{Composite Material Model}

It was assumed that the composite laminate had a linear elastic behaviour until failure. Lamina properties (Table 4) were taken from the literature [10, 19]. As was shown in [9] bending strength is higher than tensile strength for composite materials. This can be explained in terms of the statistical variation in fibre strength which dominates failure initiation. In the in-plane tension test all the fibres experience a uniform stress and so the weakest will fail first. In the beam test only the back face experiences the maximum stress and the weakest fibres are not necessarily at the back face. To take into account this effect $40 \%$ strength was increased in the numerical simulations.

To predict the composite failure, Hou and Hashin criteria were implemented in a threedimensional model by a user subroutine VUMAT in ABAQUS/Explicit which included failure criteria, stiffness degradation of damage elements and an element-deletion criterion. Under a given load, the stresses at each integration point in the composite beam are computed in the user subroutine. Then the failure criteria are evaluated and, if any failure occurs, the elastic properties at that element must be degraded according to the mode of failure. A degradation procedure was introduced into the user subroutine to reproduce the damage to the material. When a finite element was damaged (failure criterion verified) the stresses on that element were reduced almost to zero to reproduce the elastic-property degradation. To avoid sudden changes in the stiffness of the finite elements when damage occurred, and thus instability problems during the simulation, the stress components were corrected using a smooth transition following the equation 
proposed by Lopez-Puente et al [36]. Each failure criterion leads to different mechanical properties degradation, thus the updated stresses depend on the failure mode, table 5. During the numerical simulations several composite elements were damaged, the stiffness of these elements was reduced, and therefore large deformations appeared. These damaged elements did not contribute to the strength or the stiffness of the sandwich beam; however, they could produce lack of convergence during simulation, thus the simulations required an erosion criterion. Maximum-strain criteria were included in the user subroutine to remove distorted elements: after each time increment the longitudinal strains $\left(\varepsilon_{11}, \varepsilon_{22}\right.$ and $\left.\varepsilon_{33}\right)$ were evaluated and the element was removed when one of them reached a critical value equal to 0.02 .

\subsection{Test Models}

Several FE models, according to the experimental tests (Table 2), were developed to validate the material behaviour model and compare Hou and Hashin failure criteria. These models include three solids: composite beam, impactor, and support device. The impactors and the support devices were made of steel $(\mathrm{E}=210 \mathrm{GPa}, \mathrm{v}=0.3)$. Since no plastic deformation was detected in these devices after dynamic bending tests, a linear elastic behaviour was used.

Two impactor models were used, one of them to model the drop-weight tower tests (UN1, UN2, UN3 and CP1) and the other one to model the Hopkinson bar tests (CP2 and CP3), Fig. 2. The impactor model shapes reproduced the most important impactor characteristics to reproduce the tests: mass, length and nose radius. The impactor noses were meshed in great detail given that they make contact with the composite beams, Fig. 3. Impactor models were meshes using 4-node tetrahedral elements (C3D4 in ABAQUS) for the nose and 8-node brick elements with reduced integration (C3D8R in ABAQUS) for the stick.

Geometry and dimensions of the beam models were equal to those belonging to real specimens (Table 2). Beam models were meshed using the structured meshing technique and C3D8R elements. The meshes were especially dense towards the impact area, Fig. 3. The beams meshes included one element per ply along the thickness to reproduce the stacking sequence of the laminate. In all test configurations, the beams were simply supported. The support models reproduced the contact radius using a structured hexahedral mesh including C3D4 and C3D8R elements.

An interaction contact was defined between the impactor surface and a node region that included all the plies of the beam because the upper ply of the composite beam was damage. In contrast, since damage was not found in the contact between the supports and the beams, the interaction contact with the supports was defined between the supports surface and the beam lower ply. Impact energy was imposed by defining an initial velocity for the impactor.

Before performing further simulations, the sensitivity of the meshes was evaluated by carrying out successive space discretizations. The selected meshes consisted of 4796 
elements on the impactor and 4431 elements on the supports for the models of the dropweight tower tests (UN1, UN2, UN3 and CP1), while the meshes for the Hopkinson bar tests consisted of 400 elements on the supports, and 1817 and 2017 on the impactors for the CP2 and CP3 test models respectively. The beams of the UN1 tests were meshed using 11200 elements, the beams of the UN2, UN3 and CP1 test with 12000 elements, and the beams of the CP2 and CP3 with 14910 elements. asd to

\section{RESULTS}

\subsection{Validation}

Several variables were selected to validate the numerical models, peak load, and maximum deflection for all laminates, and load history for UN1, UN2, UN3, and CP1 laminates. Peak loads, time at failure and the trend of the curves obtained in the numerical simulations agree with the experimental results for both unidirectional and cross-ply laminate beams.

By way of example, Figs. 4 and 5 show the good correlation between the experimental tests (UN1 and CP1) and numerical results for the load history. Differences in the behaviour of unidirectional and cross-ply laminates can be seen in these curves. In unidirectional laminates, when the peak load is reached there was a sudden drop due to the fibre failure of the bottom layer showing a brittle behaviour for these laminates. On the contrary, in cross-ply laminates, a progressive load drop was observed after the maximum value due to the failure of the lower $90^{\circ}$ ply by matrix cracking, and then a sudden drop was produced by the failure of the bottom $0^{\circ}$ ply by fibre failure. These damage mechanics showed a more ductile behaviour in cross-ply laminates.

Tables 6 and 7 show peak load and maximum deflection plotted from numerical simulations and compared with experimental data. Small differences could be appreciated, but consistently lower than $7.5 \%$. Thus, the model simulated impacts over composite laminated beams, estimating with adequate precision the peak load and the maximum deflection. Variations in the main variables of the impact event such as span ratio, impact energy, laminate lay-ups, and test device, did not influence the precision of the model using either Hou or Hashin criteria.

Despite the different formulation of the two criteria the accuracy of the model was quite similar using Hou or Hashin criteria; the maximum difference between experimental and numerical results at peak load was $6.6 \%$ using Hou and $7.3 \%$ using Hashin criteria, and at maximum deflection was $6.4 \%$ using Hou and $7.4 \%$ using Hashin criteria. The maximum difference using Hou criteria was found in a test over a cross-ply laminate beam, while using Hashin criteria the maximum difference was found in a test over a unidirectional laminate beam. In addition, a difference of $11.2 \%$ at peak load and $12.5 \%$ in maximum deflection was observed in the comparison between Hou and Hashin 
criteria. Thus a detailed comparison between Hou and Hashin criteria was required to analyse the failure-criteria modes.

\subsection{Failure-criteria comparison}

After the numerical model was demonstrated to be precise enough to estimate force history and maximum deflection, the main failure modes in each test just before the beam failure were analysed to compare Hou and Hashin criteria. It was found that the failure modes depended especially on the laminate lay-up, and thus the result analysis was divided into results for unidirectional and cross-ply laminates.

\section{Unidirectional laminates}

The failure process in unidirectional laminate beams was similar using either Hou or Hashin criteria: the top layer was the first to be damaged by matrix crushing due to the impactor pressure, but it did not reach complete failure. Once the mechanical properties on top layer were degraded the beam bending stiffness was reduced and the failure occurred on bottom layer by tensile fibre failure. This failure mechanism corresponded to that observed in the video recording made with the high-velocity camera, Fig.6. The five failure modes were analysed in each simulation, revealing that fibre tensile failure was the failure mode responsible for the load drop in unidirectional laminate beams. Delamination was not produced before the load drop despite it is the failure mode which produced a lager damage area.

Fig. 7 shows the fibre-failure criterion, be it tension or compression, calculated in the middle cross-section using Hou and Hashin criteria for each test configuration. Despite the similar failure process, differences between Hashin and Hou criteria can be found in Fig. 7. Tensile and compressive fibre-failure criteria were almost symmetric using Hashin criteria but Hou criteria gave different results in plies subjected to tensile or compressive loads. Hashin compressive-fibre criterion considers only normal stress, $\sigma_{11}$, while Hou fibre criterion also considers shear stresses, $\sigma_{12}$ and $\sigma_{13}$, and thus the normal load exerted by the impactor over the upper ply was taken into account only by Hou criteria. As a result, according to Hou criteria, the load history underwent a sudden fall after reaching the peak load (Fig. 4), because the pressure exerted by the impactor was considered not in the matrix-failure criteria but in the fibre compressive criterion, on the contrary, the failure using Hashin criteria was more progressive, corresponding to similar values in tensile and compressive-failure criteria. This difference led to higher values of load and displacement using Hou than using Hashin criteria (Tables 6 and 7). In unidirectional laminate beams Hou criteria resulted in a sudden failure, while Hashin caused a more progressive failure, and therefore Hou criteria could be indicated to model a brittle composite material, and Hashin to model a relative ductile composite material. Failure modes and the accuracy of failure criteria were affected by neither the span ratio nor the impact energy. 


\section{Cross-ply laminates}

As in unidirectional laminate beams, the failure process in cross-ply laminate beams was analogous using Hou or Hashin criteria: the upper $90^{\circ}$ ply was the first to be damaged by matrix crushing (Figs. $8 \mathrm{~b}$ and $8 \mathrm{~d}$ ). However, it did not reach complete failure, but only degradation of mechanical properties. Once the beam stiffness was degraded, the failure was produced in the lower $90^{\circ}$ ply by matrix cracking (Figs. 8a and 8c) resulting in a progressive load drop after the peak load, then fibre failure in the bottom $0^{\circ}$ ply produced a sudden load drop.

The five failure modes were analysed in each simulation, indicating that matrix cracking was the failure mode responsible for the load drop just after the peak load in the crossply laminate beams. As took place in unidirectional beams, delamination was not produced before the load drop despite it is the failure mode which produced a lager damage area. Matrix-tensile and compressive-failure criteria were calculated in the middle cross-section just before the beam failure using Hou and Hashin criteria for each test configuration. Fig. 8 shows matrix failure criteria in the middle cross-section for $\mathrm{CP} 1$ and $\mathrm{CP} 2$ tests. Since similar results were found in the CP2 and CP3 tests, the results of the $\mathrm{CP} 3$ test are not presented here for brevity.

Some differences can be found between Hou and Hashin criteria in Fig. 8. Hashin formulation considers the effect of normal stresses, $\sigma_{33}$ and $\sigma_{13}$, in both the matrixcrushing and matrix-cracking failure criteria, this formulation leading to higher values in failure criteria and into a wider damaged area (Fig. 8). However, the differences between the results provided by Hou and Hashin criteria were lower in cross-ply laminate beams than in unidirectional ones (Tables 6 and 7). The main stress considered by Hashin criteria and avoided by Hou criteria was the normal stress, $\sigma_{33}$. This normal stress, produced by the pressure exerted by the impactor over the upper plies, was divided by the matrix compressive strength (Table 1), which was substantially higher than the tensile strength (Table 4). Thus the main factor in the matrix-crushing formulation, both in Hou and Hashin criteria, was the linear term of the transverse stress, $\sigma_{22}$, divided by the matrix compressive strength. The influence of the test device and the constituent material on failure modes and the accuracy of failure criteria could be disregarded on comparing the images in Fig. 8.

\section{CONCLUSIONS}

In this work, the failure of composite laminated beams subjected to low-velocity impacts has been analysed by a FE model implemented in ABAQUS/Explicit. A comparison was made between Hou and Hashin failure criteria under dynamic conditions. Experimental tests developed in a drop-weight tower and experimental results available in the literature were used to validate the numerical model. Different laminate lay-ups, specimen spans, and experimental devices were used in the validation 
process. The numerical values of load and displacement found agree well with the experimental results.

Differences in the prediction of the failure of composite beams between Hou and Hashin criteria were stated to be a useful tool for the researchers in the selection of a failure criteria set in the simulation of dynamic problems.

The numerical model allowed the analysis of the failure modes in both unidirectional and cross-ply laminate beams predicted by Hou and Hashin criteria.

Both criteria show that the main failure mechanism in unidirectional laminate beams under low-velocity impacts is fibre tensile failure. Hou criteria predict a sudden failure in unidirectional laminate beams, whereas the failure predicted by Hashin criteria is more progressive. For this reason, it is suggested that Hashin criteria could be suitable to model ductile composite material and the Hou criteria for brittle materials in unidirectional laminate beams.

Both criteria agree with sufficient accuracy when reproducing the behaviour of crossply laminate beams, and show that the main mechanism in these laminates is matrix cracking. Negligible differences were detected between the two criteria in both of the cross-ply laminates analysed.

\section{Acknowledgements}

The authors are indebted to the Spanish Comisión Interministerial de Ciencia y Tecnología (TRA2007-66555) for the financial support of this work.

\section{REFERENCES}

1.Turon A, Costa J, Maimi P, Trias D, and Mayugo JA. A progressive damage model for unidirectional fibre-reinforced composites based on fibre fragmentation. Part I: Formulation. Composites Science and Technology 2005, 65(13):2039-2048.

2. Davies GAO, Hitchings D; Wang J. Prediction of threshold impact energy for onset of delamination in quasi-isotropic carbon/epoxy composite laminates under lowvelocity impact. Composite Science and Technology 2000; 60(1): 1-7. 3. Sanchez-Saez S, Barbero E, Zaera R, Navarro C. Compression after impact of thin composite laminates. Composite Science and Technology 2005; 65(13): 1911-1919. 4. Chan S, Fawaz Z, Behdinan K, Amid R. Ballistic limit prediction using a numerical model with progressive damage capability. Composite Structures 2007; 77(4): 466-474. 5. Sanchez-Saez S, Barbero E, Navarro C. Compressive residual strength at low temperatures of composite laminates subjected to low-velocity impacts Composite Structures 2007; 85(3): 226-232.

6. Tita V, de Carvalho J, Vandepitte D. Failure analysis of low velocity impact on thin composite laminates: Experimental and numerical approaches. Composite Structures 2008; 83(4): 413-428. 
7. Deka LJ, Bartus SD, Vaidya UK. Damage evolution and energy absorption of Eglass/polypropylene laminates subjected to ballistic impact. Journal of Materials Science 2008; 43(13): 4399-4410.

8. Sheikh AH, Bull PH, Kepler JA. Behaviour of multiple composite plates subjected to ballistic impact. Composite Science and Technology 2009; 69: 704-710.

9. Hallett SR. Three-point beam impact tests on T300/914 carbon-fibre composites. Composite Science and Technology 2000; 60: 115-124.

10. Sánchez-Sáez S, Barbero E, Navarro C. Analysis of the dynamic flexural behaviour of composite beams at low temperature. Composite Science and Technology 2007;

67(11-12): 2616-2632.

11. Sevkat E, Liaw B, Delale F, Raju BB. A combined experimental and numerical approach to study ballistic impact response of S2-glass fiber/toughened epoxy composite beams. Composite Science and Technology 2009; 69(7-8): 965-982.

12. Maimí P, Camanho P.P., Mayugo JA, and Dávila CG. A continuum damage model for composite laminates. Part II - Computational implementation and validation. of Materials 2007, 39 (10):897-908.

13. Nahas NM. Survey of failure and post-failure theories of laminated fiber-reinforced composites. Journal of Composites Technology and Research 1986; 8(4):138-153.

14. Paris F. A study of failure criteria of fibrous composite materials. Technical report: NASA-cr210661, 2001.

15. Kärger L, Baaran J, Tessmer J. Efficient simulation of low-velocity impacts on composite sandwich panels. Computer and Structures 2008; 86: 988-996.

16. Jadhav P, Mantena PR, Gibson RF. Energy absorption and damage evaluation of grid stiffened composite panels under transverse loading. Composite Part B-

Engineering 2006; 37(2-3): 191-199.

17. Greve L, Pickett AK. Delamination testing and modelling for composite crash simulation. Composite Science and Technology 2006; 66: 816-826.

18. Hashin Z. Failure criteria for unidirectional fiber composites. Journal of Applied Mechanics 1980, 47(2): 329-334.

19. Hou JP, Petrinic N, Ruiz C, Hallett SR. Prediction of impact damage in composite plates. Composite Science and Technology 2000; 60 (2): 273-28.

20. Chang F, Chang K. A progressive damage model for laminated composites containing stress concentrations. Journal of Composite Materials 1987; 21:834-55.

21. Foo CC, Chai GB, Seah LK. A model to predict low-velocity impact response and damage in sandwich composites. Composite Science and Technology 2008; 68: 13481356.

22. Minak G, Abrate S, Ghellia D, Pancirolia R and Zucchellia A. Low-velocity impact on carbon/epoxy tubes subjected to torque - Experimental results, analytical models and FEM analysis. Composite Structures 2010, 92:623-632 . 
23. Sriram R, Vaidya UK, Kim JE. Blast impact response of aluminum foam sandwich composites. Journal of Materials Science 2006; 41(13): 4023-4039.

24. Gómez-del Rio T, Zaera R, Barbero E, Navarro C. Damage in CFRPs due to low velocity impact at low temperature. Composite Part B-Engineering 2005;36 (1): 41-50.

25. Ghasemnejad H, Hadavinia $\mathrm{H}$ and Aboutorabi A. Effect of delamination failure in crashworthiness analysis of hybrid composite box structures. Materials and Design 2010, 31:1105-1116.

26. García-Castillo SK, Sánchez-Sáez S, López-Puente J, Barbero E, Navarro C. Impact behaviour of preloaded glass/polyester woven plates. Composite Science and Technology 2009; 69(6): 711-717.

27. Meo M, Morris AJ, Vignjevic R, Marengo G. Numerical simulations of lowvelocity impact on an aircraft sandwich panel. Composite Structures 2003; 62 (3-4): 353-360.

28. Nguyen MQ, Jacombs SS, Thomson RS, Hachenberg D, Scott ML. Simulation of impact on sandwich structures. Composite Structures 2005; 67:217-227.

29. Zangani D, Robinson M, Gibson AG. Energy Absorption Characteristics of WebCore Sandwich Composite Panels Subjected to Drop-Weight Impact. Applied Composite Materials 2008, 15:139-156.

30. Heimbs S, Cichosz, J, Klaus M, Kilchert S and Johnson AF. Sandwich structures with textile-reinforced composite foldcores under impact loads. Composite Structures 2010, 92:1485-1497.

31. Ivañez I, Santiuste C, Sanchez-Saez S. FEM analysis of dynamic flexural behaviour of composite sandwich beams with foam core. Composite Structures 2009.

doi:10.1016/j.compstruct.2009.07.018

32. Hashin Z, Rotem A. A fatigue failure criterion for fiber reinforced materials.

Composiste Materials 1973; 7:448-464.

33. Kim RY, Soni SR. Failure of composite laminates due to combined interlaminar normal and shear stresses. In: Kawata K, Umekawa S, Kobayashi A, editors.

Composites' 86: recent advances in Japan and the United States, Proceedings of JapanU.S. CCM-III; 1986. p. 341-350.

34. Brewer JC, Lagace PA. Quadratic stress criterion for initiation of delamination. Journal of Composite Materials 1988; 22(12):1141-55.

35. Mahanta BB, Chakraborty D and Dutta A. Accurate prediction of delamination in FRP composite laminates resulting from transverse impact. Composite Science and Technology 2004; 64: 2341-2351.

36. Lopez-Puente J, Zaera R, Navarro C. Experimental and numerical analysis of normal and oblique ballistic impacts on thin carbon/epoxy woven laminates.

Composites: Part A 2008; 39:374-387. 


\section{FIGURE CAPTIONS}

Fig 1. History loads in representative specimens of UN1, UN2 and UN3 configurations Fig. 2. Impactor models. a) Experimental drop-weight tower impactor; b) Drop-weight tower impactor model; c) Hopkinson bar impactor model for CP3 test; d) Hopkinson bar impactor model for CP2 test.

Fig. 3. Beam and impactor nose meshes. a) UN1 specimen, b) UN2, UN3, and CP1 specimens, c) CP2 and CP3 specimens.

Fig 4. Comparison between experimental and numerical load history for UN1 test.

Fig 5. Comparison between experimental and numerical load history for CP1 test.

Fig 6. Unidirectional laminate beam test (UN2). Comparison between experimental test and numerical simulation, $\mathrm{t}=3.5 \mathrm{~ms}$. a) Experimental test photograph, b) Numerical simulation picture.

Fig 7. Fibre-failure criteria on unidirectional laminate beams, a) UN1 test, b) UN2 test, c) UN3 test.

Fig 8. Matrix-failure criteria in cross-ply laminate beams. a) Matrix cracking in CP1 test, b) Matrix crushing in CP1 test, c) Matrix cracking in CP2 test, d) Matrix crushing in $\mathrm{CP} 2$ test.

\section{TABLE CAPTIONS}

Table 1. Hou and Hashin failure-criteria formulation.

Table 2. Test configurations.

Table 3. Peak load and maximum deflection observed in the experimental tests.

Table 4. Lamina properties.

Table 5. Stress components degraded according to each failure criterion.

Table 6. Peak load. Comparison between experimental and numerical results.

Table 7. Maximum deflection. Comparison between experimental and numerical results. 


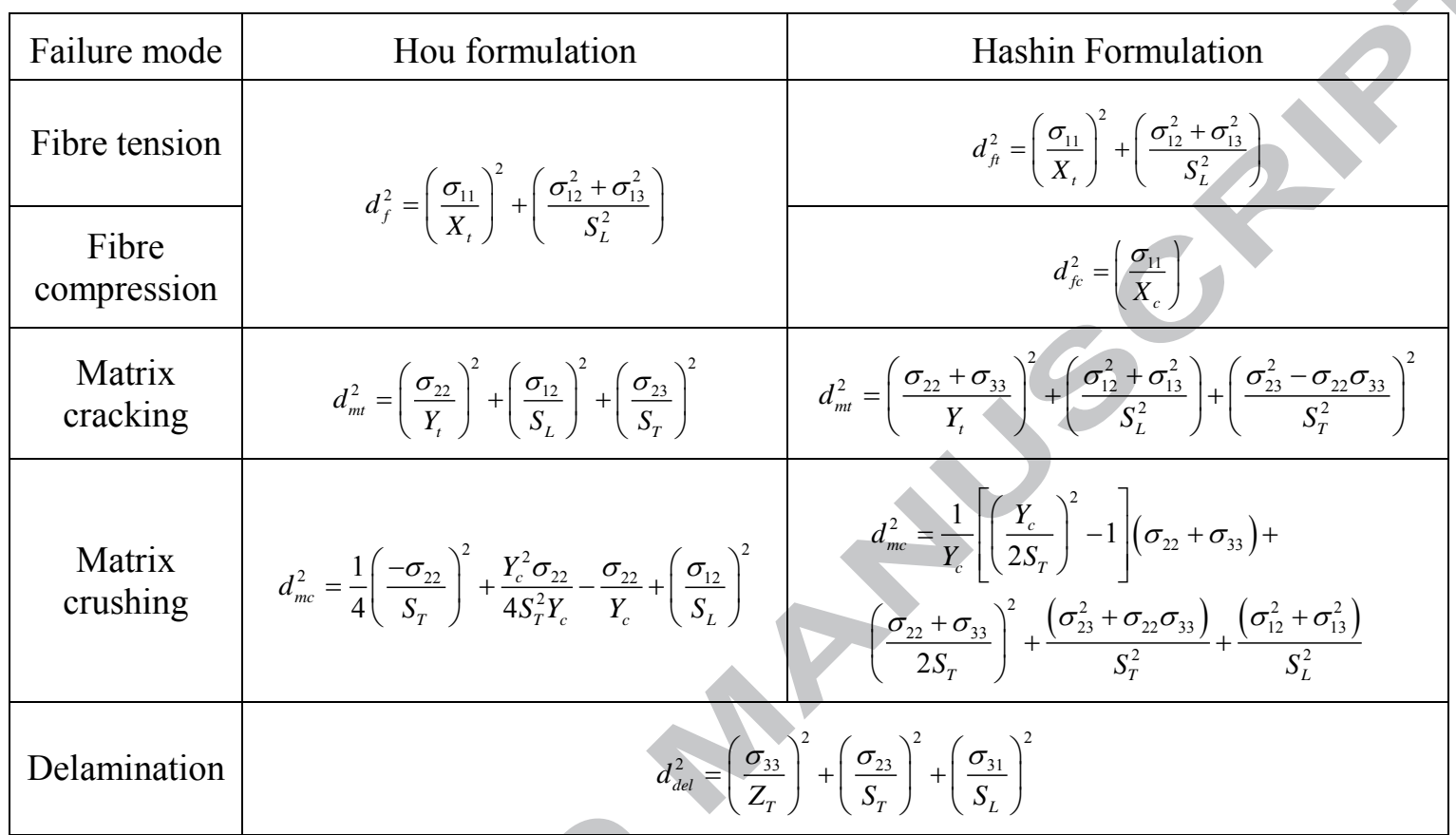

Table 1. Hou and Hashin failure-criteria formulation. 


\begin{tabular}{|c|c|c|c|c|c|c|}
\cline { 2 - 7 } \multicolumn{1}{c|}{} & Material & Lay-up & $\begin{array}{c}\text { Span } \\
(\mathrm{mm})\end{array}$ & $\begin{array}{c}\text { Thickness } \\
(\mathrm{mm})\end{array}$ & $\begin{array}{c}\text { Width } \\
(\mathrm{mm})\end{array}$ & $\begin{array}{c}\text { Impact } \\
\text { energy }(\mathrm{J})\end{array}$ \\
\hline $\mathrm{UN} 1$ & AS4/3501-6 & {$[0]_{10}$} & 50 & 2 & 20 & 20 \\
\hline $\mathrm{UN} 2$ & AS4/3501-6 & {$[0]_{10}$} & 80 & 2 & 20 & 20 \\
\hline $\mathrm{UN} 3$ & $\mathrm{AS} 4 / 3501-6$ & {$[0]_{10}$} & 80 & 2 & 20 & 30 \\
\hline $\mathrm{CP} 1$ & $\mathrm{AS} 4 / 3501-6$ & {$[0 / 90]_{3 \mathrm{~S}}$} & 80 & 2.4 & 20 & 20 \\
\hline $\mathrm{CP} 2$ & $\mathrm{~T} 300 / 914$ & {$[0 / 90]_{5 \mathrm{~S}}$} & 95 & 2.55 & 10 & 2.10 \\
\hline $\mathrm{CP} 3$ & $\mathrm{~T} 300 / 914$ & {$[0 / 90]_{5 \mathrm{~S}}$} & 95 & 2.55 & 10 & 2.75 \\
\hline
\end{tabular}

Table 2. Test configurations. 


\begin{tabular}{|c|c|c|c|c|}
\hline \multirow{2}{*}{ Test } & \multicolumn{2}{|c|}{ Peak Load } & \multicolumn{2}{c|}{ Maximum Deflection } \\
\cline { 2 - 5 } & $\begin{array}{c}\text { Mean value } \\
(\mathrm{N})\end{array}$ & $\begin{array}{c}\text { Coef. of Variation } \\
(\%)\end{array}$ & $\begin{array}{c}\text { Mean value } \\
(\mathrm{mm})\end{array}$ & $\begin{array}{c}\text { Coef. of Variation } \\
(\%)\end{array}$ \\
\hline UN1 & 1732 & 4.45 & 3.78 & 5.82 \\
\hline UN2 & 1009 & 5.25 & 9.58 & 5.11 \\
\hline UN3 & 1004 & 2.19 & 9.45 & 4.02 \\
\hline
\end{tabular}

Table 3. Peak load and maximum deflection observed in the experimental tests. 


\begin{tabular}{|l|c|c|}
\cline { 2 - 3 } \multicolumn{1}{l|}{} & AS4/3501-6 & T300/914 \\
\hline Young modulus in fibre direction, E1 $(\mathrm{GPa})$ & 118 & 139 \\
\hline Young modulus in transverse direction, E2 $(\mathrm{GPa})$ & 10 & 9.4 \\
\hline Young modulus in normal direction, $\mathrm{E} 3(\mathrm{GPa})$ & 0.0237 & 0.0209 \\
\hline Poisson's ratio, $v_{12}$ & 0.0237 & 0.0209 \\
\hline Poisson's ratio, $v_{13}$ & 0.4 & 0.33 \\
\hline Poisson's ratio, $v_{23}$ & 6.2 & 4.5 \\
\hline Shear modulus, G12 $(\mathrm{GPa})$ & 6.2 & 4.5 \\
\hline Shear modulus, G13(GPa) & 4.1 & 2.98 \\
\hline Shear modulus, G23 $(\mathrm{GPa})$ & 1930 & 2070 \\
\hline Tensile mechanical strength in fibre direction, $\mathrm{X}_{\mathrm{T}}(\mathrm{MPa})$ & 1390 & 2070 \\
\hline Compressive mechanical strength in fibre direction $\mathrm{X}_{\mathrm{C}}(\mathrm{MPa})$ & 45 & 74 \\
\hline Tensile mechanical strength in transverse direction $\mathrm{Y}_{\mathrm{T}}(\mathrm{MPa})$ & 188 & 237 \\
\hline Compressive mechanical strength in transverse direction $\mathrm{Y}_{\mathrm{C}}(\mathrm{MPa})$ & 45 & 74 \\
\hline Tensile mechanical strength in normal direction $\mathrm{Z}_{\mathrm{T}}(\mathrm{MPa})$ & 73 & 120 \\
\hline Longitudinal shear strength $\mathrm{S}_{\mathrm{L}}(\mathrm{MPa})$ & 52 & 64 \\
\hline Transverse shear strength $\mathrm{S}_{\mathrm{T}}(\mathrm{MPa})$ & 1580 \\
\hline Density, $\rho\left(\mathrm{Kg} / \mathrm{m}^{3}\right)$ & & \\
\hline
\end{tabular}

Table 4. Lamina properties. 


\begin{tabular}{|c|c|c|c|c|c|c|}
\hline Failure mode & $\sigma_{11}$ & $\sigma_{22}$ & $\sigma_{33}$ & $\sigma_{12}$ & $\sigma_{13}$ & $\sigma_{23}$ \\
\hline Fibre failure & $\mathrm{x}$ & $\mathrm{x}$ & $\mathrm{x}$ & $\mathrm{x}$ & $\mathrm{x}$ & $\mathrm{x}$ \\
\hline Matrix cracking & & $\mathrm{x}$ & $\mathrm{x}$ & $\mathrm{x}$ & & \\
\hline Matrix crushing & & $\mathrm{x}$ & $\mathrm{x}$ & & & \\
\hline Delamination & & & $\mathrm{x}$ & & $\mathrm{x}$ & $\mathrm{x}$ \\
\hline
\end{tabular}

Table 5. Stress components degraded according to each failure criterion. 


\begin{tabular}{|c|ccc|cc|c|}
\cline { 2 - 6 } \multicolumn{1}{c|}{} & \multicolumn{3}{|c|}{ Peak Load (N) } & \multicolumn{2}{|c|}{$\begin{array}{c}\text { Difference with } \\
\text { exp. results (\%) }\end{array}$} & $\begin{array}{c}\text { Difference } \\
\text { Hou \& }\end{array}$ \\
\cline { 2 - 5 } \multicolumn{1}{c|}{} & Experimental & $\begin{array}{c}\text { Hou } \\
\text { criteria }\end{array}$ & $\begin{array}{c}\text { Hashin } \\
\text { criteria }\end{array}$ & $\begin{array}{c}\text { Hou } \\
\text { criteria }\end{array}$ & $\begin{array}{c}\text { Hashin } \\
\text { criteria }\end{array}$ & criteria (\%) \\
\hline UN1 & 1732 & 1834 & 1681 & -5.9 & 2.9 & 8.3 \\
UN2 & 1009 & 998 & 935 & 1.1 & 7.3 & 6.3 \\
UN3 & 1004 & 1065 & 946 & -6.1 & 5.8 & 11.2 \\
\hline CP1 & 988 & 991 & 975 & -0.3 & 1.3 & 1.6 \\
\hline CP2 & 630 & 656 & 640 & -4.1 & -1.6 & 2.4 \\
CP3 & 638 & 680 & 640 & -6.6 & -0.3 & 5.9 \\
\hline
\end{tabular}

Table 6. Peak load. Comparison between experimental and numerical results. 


\begin{tabular}{|c|c|c|c|c|c|c|}
\hline & \multicolumn{3}{|c|}{ Max. Deflection (mm) } & \multicolumn{2}{|c|}{$\begin{array}{l}\text { Difference with } \\
\text { exp. results }(\%)\end{array}$} & \multirow{2}{*}{$\begin{array}{c}\text { Difference } \\
\text { Hou \& } \\
\text { Hashin } \\
\text { criteria }(\%)\end{array}$} \\
\hline & Experimental & $\begin{array}{l}\text { Hou } \\
\text { criteria }\end{array}$ & $\begin{array}{l}\text { Hashin } \\
\text { criteria }\end{array}$ & $\begin{array}{c}\text { Hou } \\
\text { criteria }\end{array}$ & $\begin{array}{l}\text { Hashin } \\
\text { criteria }\end{array}$ & \\
\hline UN1 & 3.78 & 4.00 & 3.50 & -5.8 & 7.4 & 12.5 \\
\hline UN2 & 9.58 & 9.50 & 8.96 & 0.8 & 6.5 & 5.7 \\
\hline UN3 & 9.45 & 10.00 & 9.05 & -5.8 & 4.2 & 9.5 \\
\hline $\mathrm{CP} 1$ & 8.71 & 8.65 & 8.60 & 0.7 & 1. & 0.6 \\
\hline $\mathrm{CP} 2$ & 8.78 & 8.22 & 8.50 & 6.4 & 3.2 & -3.4 \\
\hline $\mathrm{CP} 3$ & 8.74 & 8.30 & 8.55 & 5.0 & 2.2 & -3.0 \\
\hline
\end{tabular}

Table 7. Maximum deflection. Comparison between experimental and numerical results. 


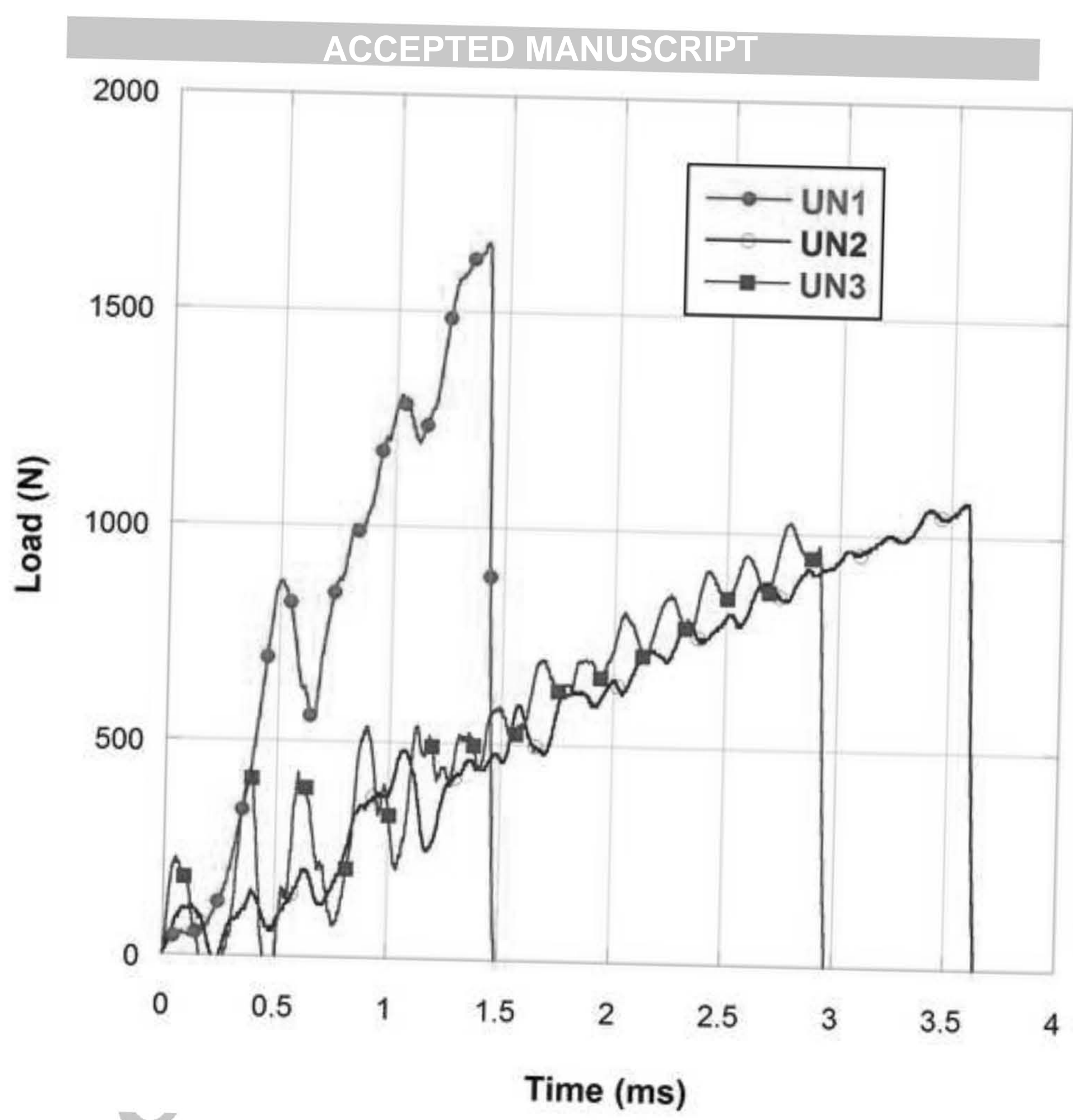



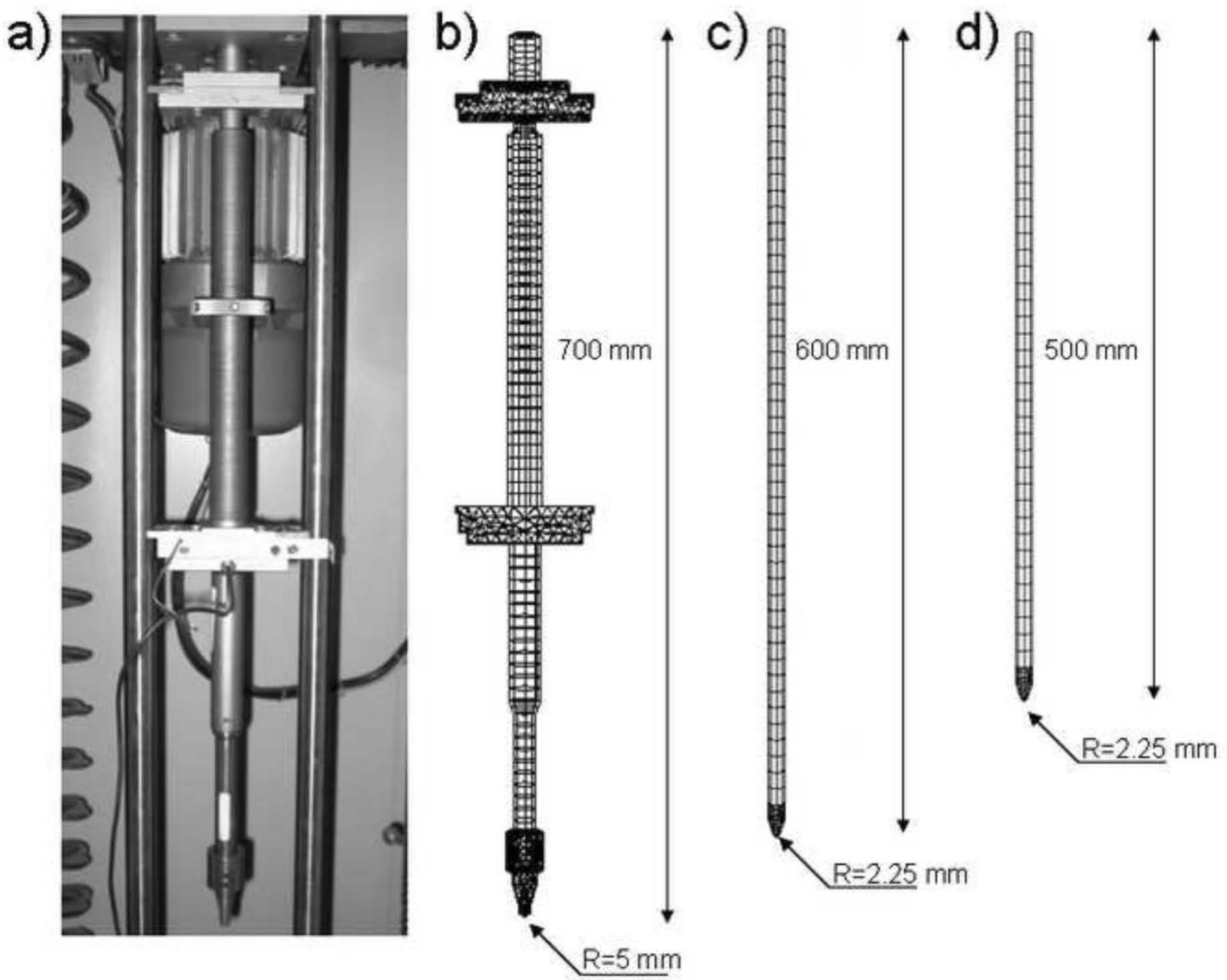
a)

ACCEPTED MANUSCRIPT

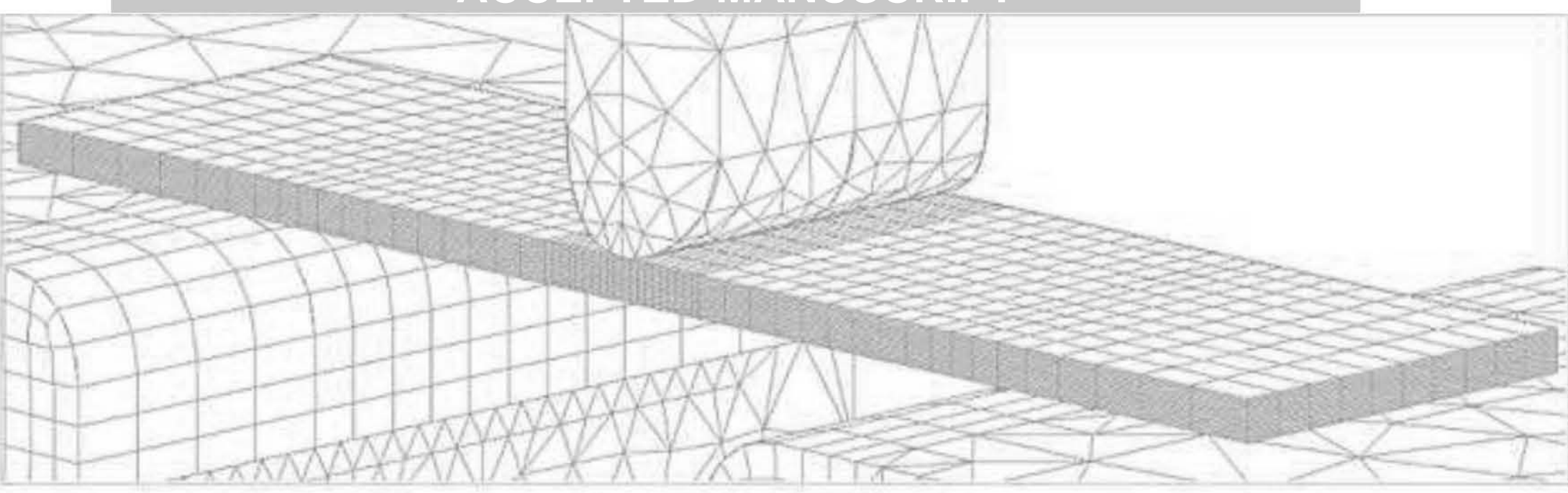

b)

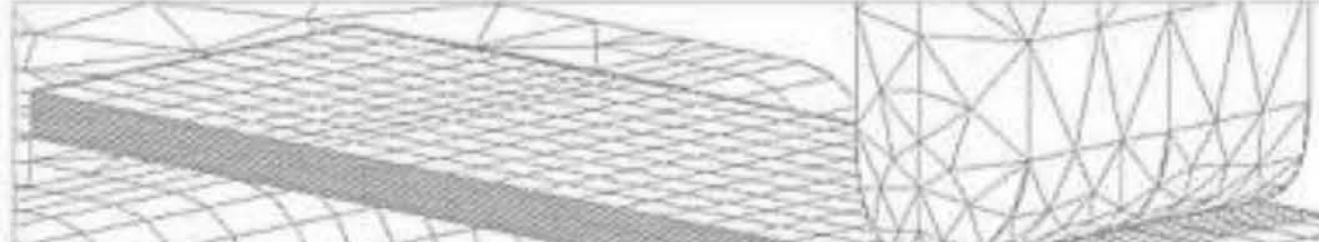

(1)

c)

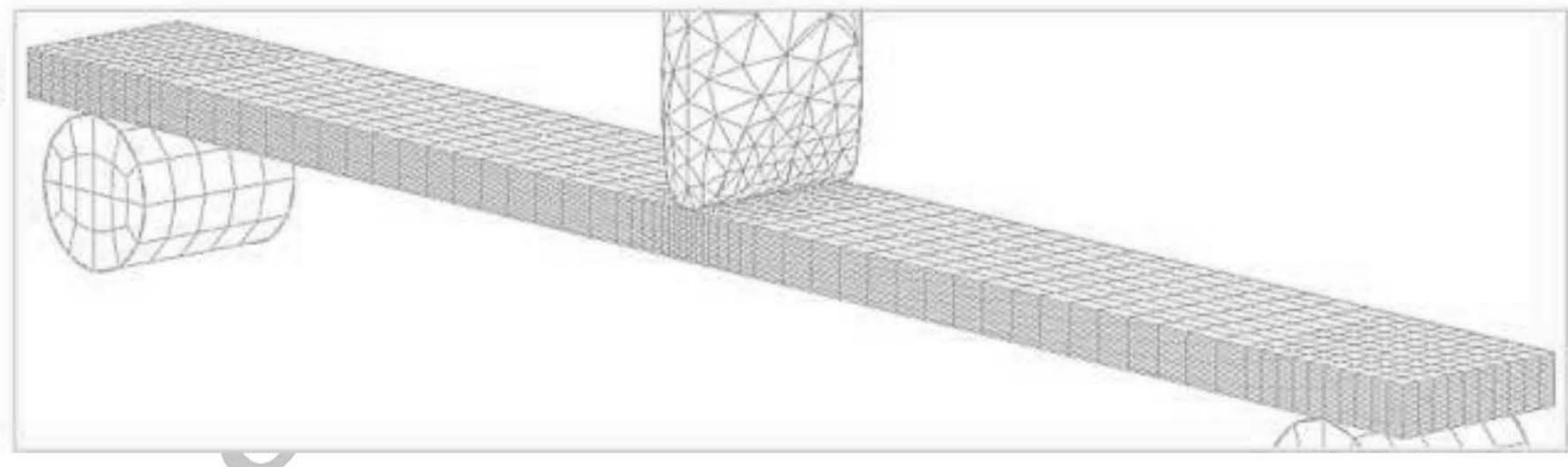




\section{ACCEPTED MANUSCRIPT}

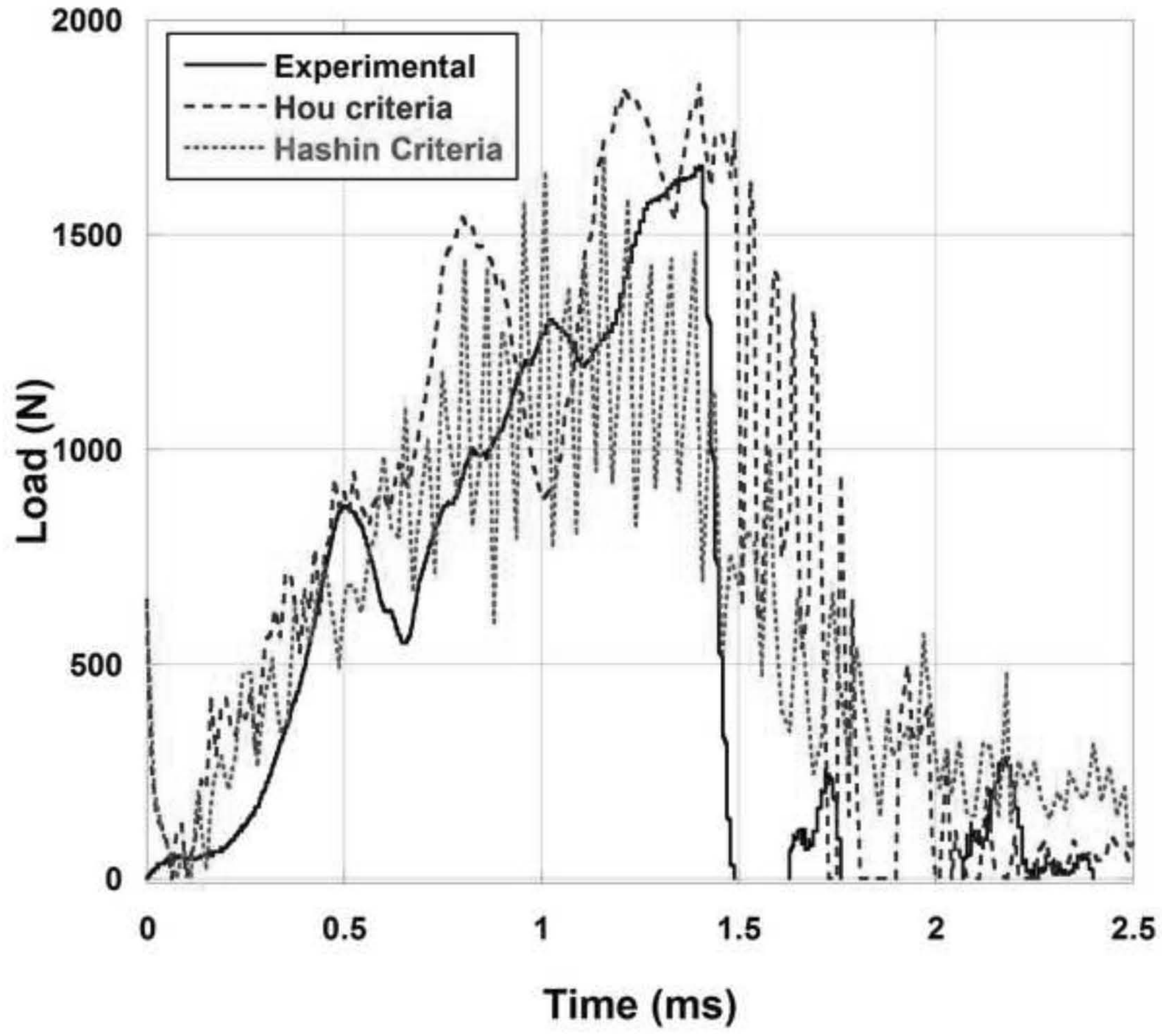





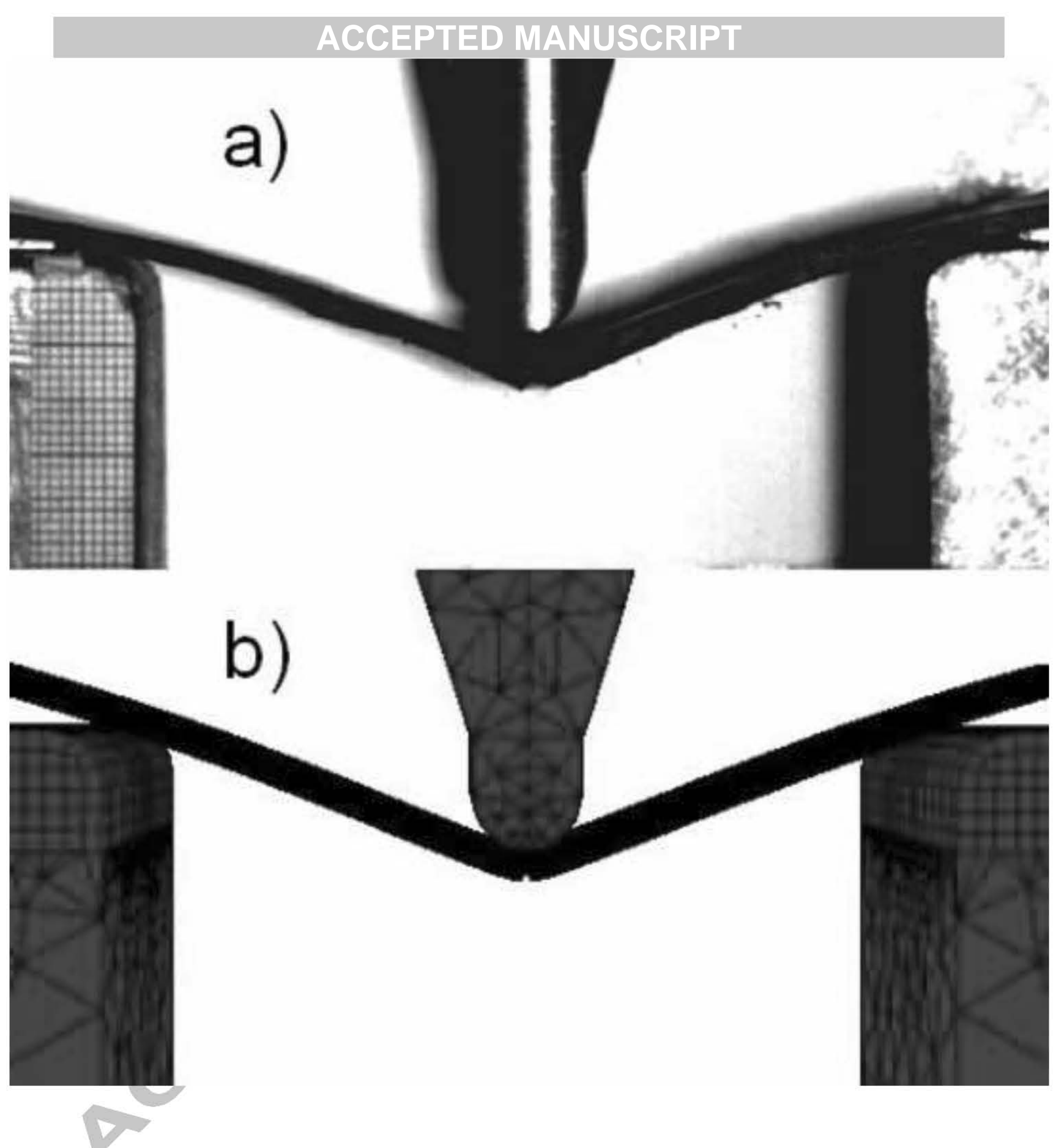



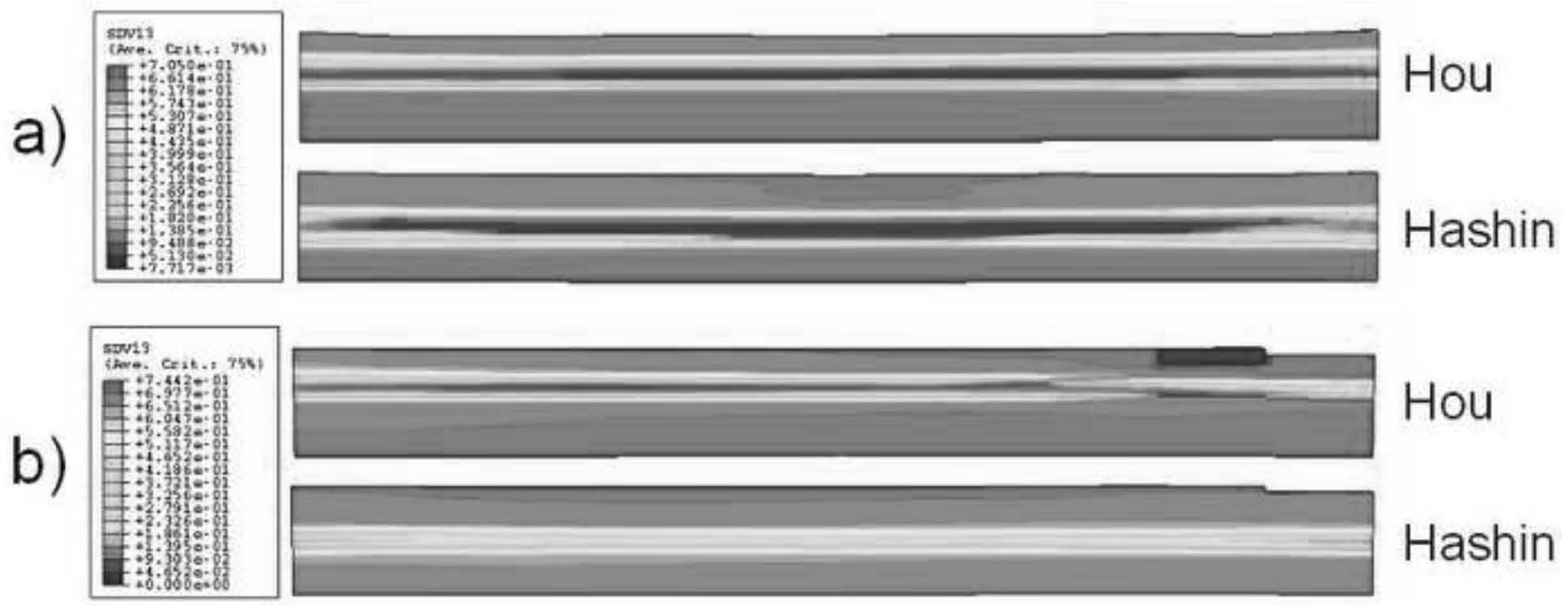

$\mathrm{Hou}$

Hashin
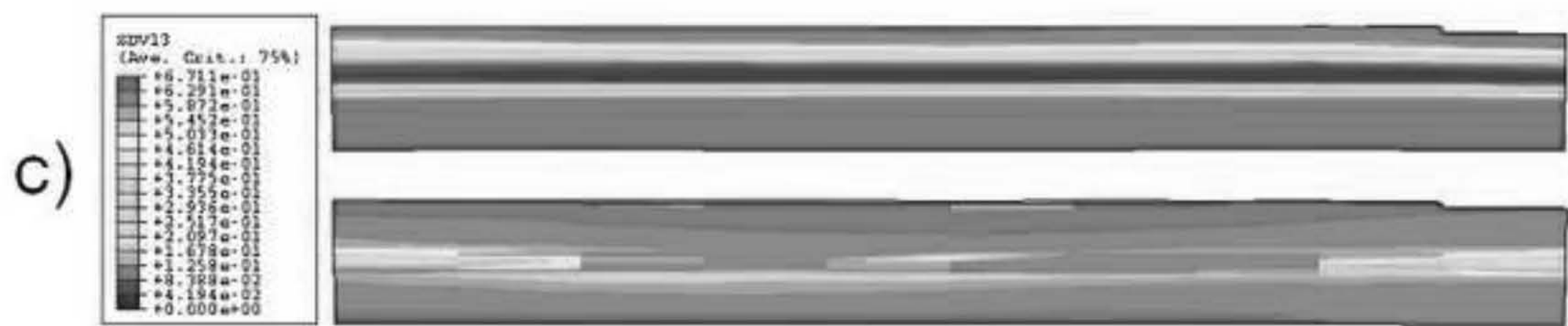

Hou

Hashin 
ACCEPTED MANUSCRIPT
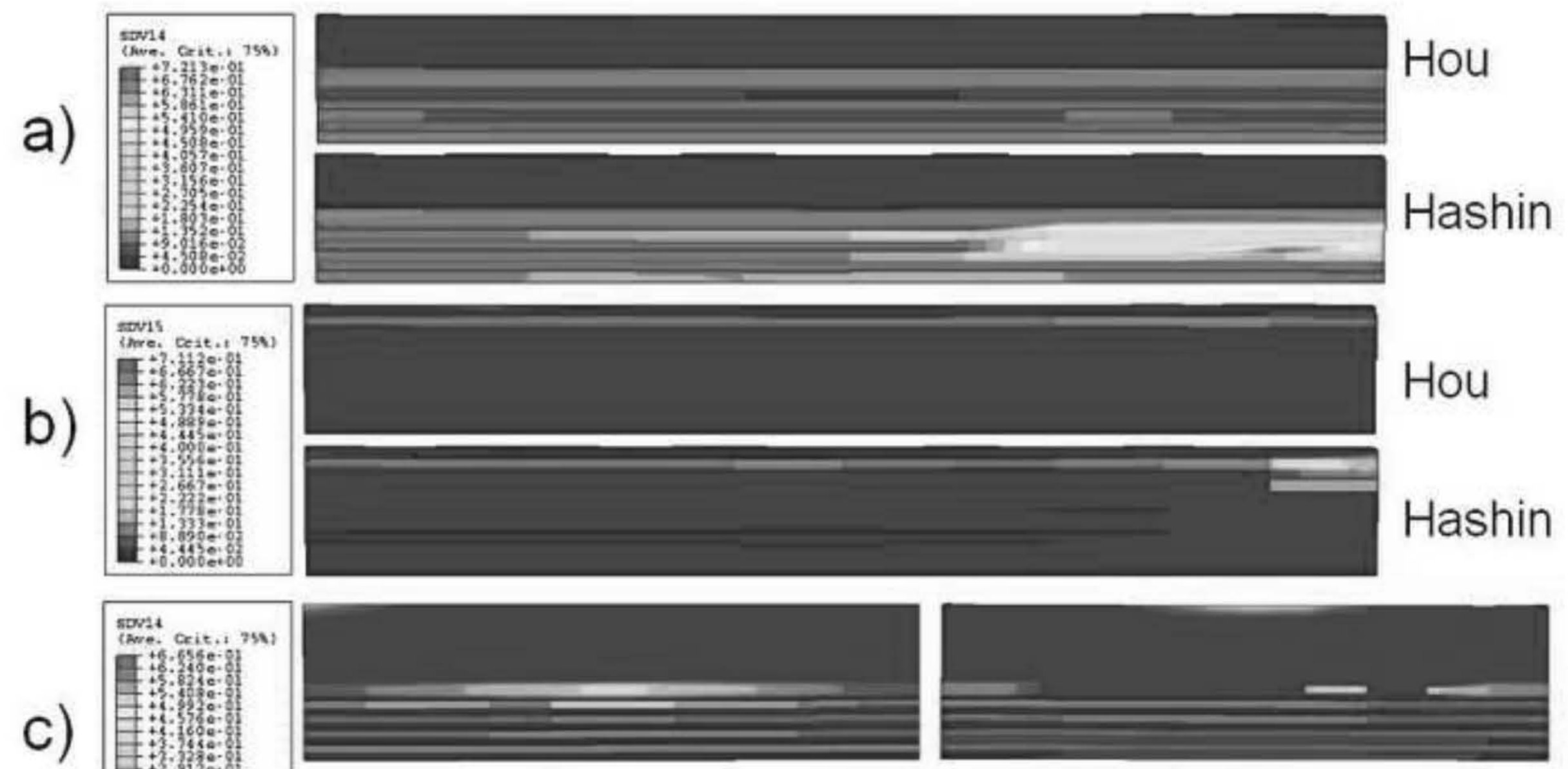

Hou

$\mathrm{Hou}$

Hashin

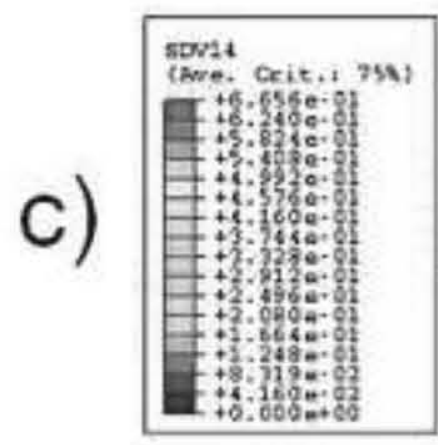

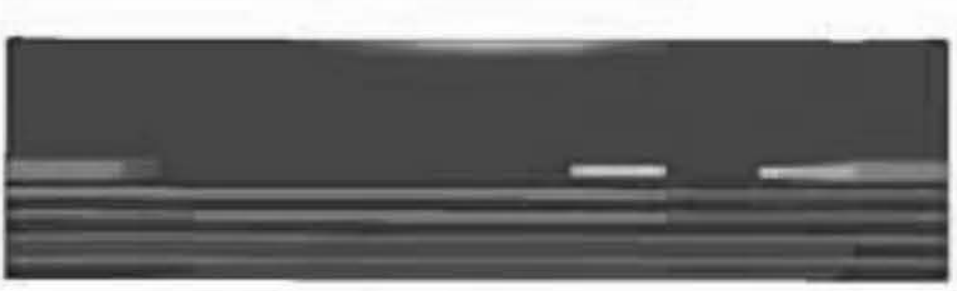

Hashin
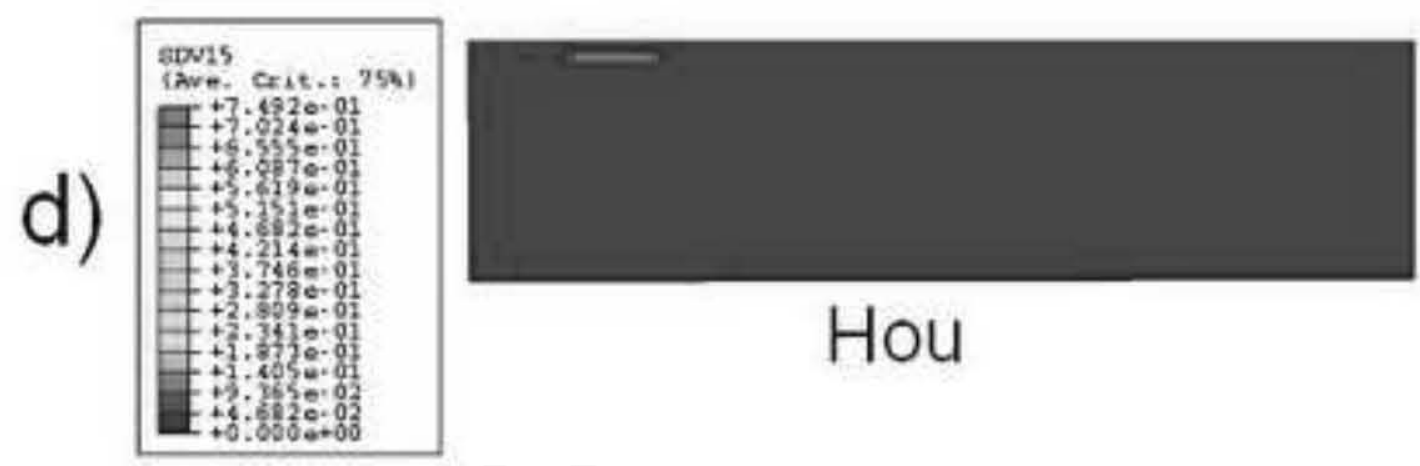

$\mathrm{Hou}$

Hashin

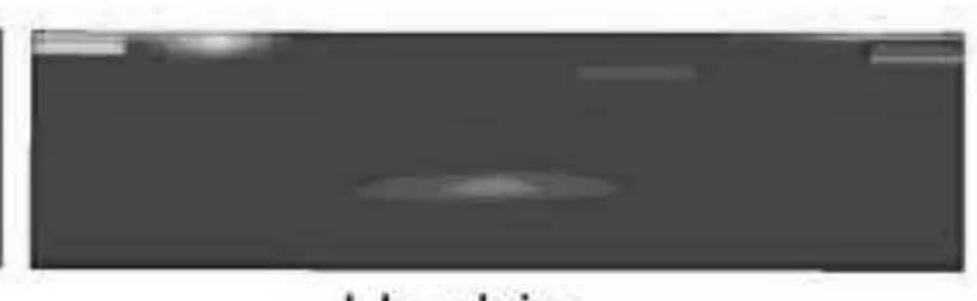

